\title{
ANTIOXIDANT BASKET: DO NOT MIX APPLES AND ORANGES
}

\author{
P P Singh and Praveen Sharma* \\ Era's Lucknow Medical College, SarfarazGanj, Hardoi Road, Lucknow, *SMS Medical College, Jaipur
}

\section{INTRODUCTION}

The intention of this editorial is neither to undermine the importance of free radicals (FR) and antioxidants (AO) in human body, nor to ridicule the FR as corpus delicti nor AO as fountains of youth and longevity, but to pinpoint convergent and divergent facts about them, raging controversies and possible reasons for the same. We would also attempt to focus on the issues on which researches on antioxidants should impinge to resolve them. The alluring hypotheses are numerous which are based on half baked facts, resulting in intertwined controversies. The priority of the day for this attractive area of research is to make it more captivative by dispelling rose petal fantasies $(1,2)$.

The ROS (for the sake of brevity ROS refers to both reactive oxygen species and reactive nitrogen species) generation in aerobic organisms including humans is an aberrant inevitable evolutionary phenomenon or systematically developed vocation is only a matter of speculation, but it is undisputably clear that ROS at low concentration in humans induce defence genes, adaptive responses, regulate transcriptional factors and apoptosis and strengthen immune system. On the contrary, in the persistent mild or moderate concentration of these are in all possibility copartners in etiopathogenesis of cancer, cardiovascular disease, diabetes mellitus, Alzheimer's disease, chronic lung disease progression, progeria and many other diseases through diverse mechanisms. So far there is no implicit evidence that ROS accumulate in high concentration in human tissues or are sole cause of any disease. The reason is body possesses a well knit "Antioxidant Defence System" consisting of endogenous (enzymic and nonenzymic) and nutrient antioxidants, vitamin $C$ and $E$ and betacarotene (to some extent vitamin A also). Diet, beside nutrient

\section{Address for Correspondence :}

Prof. P. P. Singh

Era's Lucknow Medical College, Sarfaraz Ganj, Hardoi Road, Lucknow

E-mail : dr_pp_singh@yahoo.com antioxidants, contains a variety of other antioxidants such as carotenoids, polyphenols, which augment the antioxidant battery. But unfortunately, the unproven presumptions have been the cause of quagmire. Ablative approach has become necessary to sort out facts from fictions (2).

\section{ANTIOXIDANTS: HOW STRONG ARE THEY?}

An antioxidant is a compound that when present at low to moderate concentration compared with those oxidizable substrates in the cellular milieu significantly delays or prevents oxidation of substrate. Thus they sacrifice themselves to safeguard the vital biomolecules such as lipids, proteins and DNA from the undesirable disasters. They are robust but resilient which makes them vulnerable.

They require team without which they become weak and when alone in excess they may turn hostile due to their accumulation as prooxidant, which is the cause of harmful effects due to supplementation as observed in clinical trials.

The two intricately convoluted issues about antioxidants are: first, why many antioxidants have failed in clinical trials whereas they have shown distinct benefits in designed in vitro, cell culture and in vivo animal studies and second, why supplementation has shown harmful effects including that exacerbating the disease or even increasing all cause mortality. The following points may partly explain their behaviour: i) the "Rank order" and "Relative importance" of "Antioxidants" is not absolute. They may be cell specific, tissue specific and species specific. For example, a chemical compound may behave as an antioxidant in rat but not in man, in liver but not in kidney, in beta-cells of Langerhans but not in alpha cells of Langerhans. Intriguingly, it may be beneficial in one organ, harmful in other organ and no effect in yet another organ. An ex-vivo study examining the effect of dietary antioxidants on healthy human lymphocyte DNA, catechin, epicatechin, epicatechin gallate, ascorbic acid and alpha-tocopherol offered no protective effect, quercetin and caffiec acid had protective effect, whereas epigallocatechin and epigallocatechin gallate 
had damaging effect. ii) if source of FR is kept same but different target molecules of oxidative damage are measured, results may differ. When human plasma is exposed to cigarette smoke in vitro, both lipid and protein oxidation proceeds. While ascorbic acid inhibits lipid peroxidation but has no effect on carbonyl formation. Very interestingly a study revealed that apple and black currant juice decreased lipid peroxidation but increased oxidative damage of proteins. iii) no antioxidant till date is known to behave as a universal antioxidant. iv) many antioxidants known to possess strong antioxidant activity perform or supervise several important non-antioxidant functions (e.g. vitamin E, C and beta-carotene $(3,7)$. v) some compounds in lower concentration behave as an effective antioxidant by inhibiting a reaction but in higher concentration provoke the same reaction. Beta-carotene in lower doses inhibits lipooxygenase activity but in higher doses stimulates the activity of the same enzyme. Higher doses also affect signal transduction processes. Such antioxidant supplements will produce adverse effects in clinical trials vi) ironically the safe level of intake of many popular nutrient antioxidants is not yet certain. Only recently, a high level committee in USA recommended the safe level of daily intake of 1000 and 2000 $\mathrm{mg}$ of vitamins $\mathrm{E}$ and vitamin C respectively (4) but the contradiction appeared in the same year. The committee could not defend its claim. vii) antioxidants work better as team, as such a proper balance has to be maintained for optimal defence network. However, we are still unclear as to what should be optimal concentration of individual antioxidants to achieve ideal defence network. viii) zealous intake may suppress the ROS level below the required level for conducting physiological activity (2). ix) In the recent years, measurement of "total antioxidant activity" (TAA) in plasma has been proposed as a better marker of antioxidant status rather than measurement of individual antioxidant as it provides global picture of antioxidant activity. Several methods are in vogue but none are perfect. Further, the picture in plasma or erythrocytes does not necessarily reflect the status in different tissues and $\mathrm{x}$ ) finally in our opinion no antioxidant is stronger or weaker, in a network, each link has a sacrosanct place and should have adequate strength to hold. infrangible relationship. Antioxidants are essence of life, are strong enough to temper the ROS within limits to organize many physiological activities. However, neither any individual antioxidants nor the total team is too strong to meet an eventuality of oxidative burst or severely enhanced generation of ROS. In such eventuality damage and disease will appear $(1,2)$.

\section{Antioxidants are getting collective flogging}

What an irony? Only few years ago antioxidant preparations were "Magic Pills" to fight against almost all diseases, but today they look like heading for dustbin history. The disgrace began with a comprehensive study demonstrating the adverse effects of beta-carotene supplementation in smokers. Thereafter a spate of reports have appeared either ridiculing the antioxidant supplementation or with no effects. Among all the antioxidants beta-carotene and vitamin $E$ which were at one time considered to be the most potent antioxidants are getting a central beating. No reason exists to recommend carotenoids in pharmaceutical form to treat CVD or other diseases. Most of the benefits of carotenoids are for their nonantioxidant actions. High doses of vitamin E supplementation increase all cause mortality. Several high rank randomized controlled trials of vitamins $A, C$ and $E$ have failed to demonstrate any consistent or significant benefit of single or combination of vitamins on the incidence of death from CVD, cancer, diabetes mellitus, aging and mortality (5-13). The breakdown of beta-carotene interferes with retinoid signalling processes and vitamin $C$ and $E$ in excess may enhance oxidizing environment thereby initiating undesirable oxidized processes. Likewise disappointing results continue to appear in literature. Keeping all the facts in mind, American Heart Science Advisory Committee on the subject of antioxidant vitamins and CVD asserted that evidence is insufficient to justify the use of antioxidant vitamin supplement for CVD risk reduction. Story does not end up here.

Some of the most recent metaanalyses reports published in 2008 and 2009 require special mention. In 2008, Clark and Burnett (7) have excellently summarized the role of vitamin $E$ in human health and disease and have concluded: a) results from large prospective, randomized, placebo controlled clinical trials have largely been negative, b) vitamin $E$ may increase all cause mortality, c) very importantly in vitro human cell culture and animal models suggest that vitamin $E$ may increase the production of cytochrome $\mathrm{P}_{450 \mathrm{~s}}$ and multidrug resistant protein in liver which may result in lower efficiency of any drug due to faster metabolization. Bijelkovic group (8) has carried out several systematic Cochrane metaanalyses on the role of antioxidants in several diseases especially cancer and have recently assessed the effect of antioxidant supplements for preventing gastrointestinal cancers and concluded: (i) fixed effect model meta-analysis revealed significantly increased mortality by antioxidant supplements; (ii) beta-carotene in combination with vitamin $A$ and $E$, significantly increased mortality; (iii) in five trials selenium seemed to show significant beneficial effect on gastrointestinal cancer incidence, but Lipman group (13) claimed that selenium or vitamin E did not prevent prostate cancer. 
Almost at the same line Gaziano group (11) in a randomized, double blind, placebo controlled factorial trial of vitamin $E$ and $C$ on 14641 male physicians aged $\geq 50$ years for ten years, who were given $400 \mathrm{IU}$ vitamin alternate day and $500 \mathrm{mg}$ vitamin $C$ daily concluded that these supplement did not reduce the risk of total cancer or prostate cancer. Supporting them Lin et al (11) corroborated that vitamin C, E and beta-carotene did not confer benefit in primary prevention of total cancer incidence or cancer mortality. Likewise, there are numerous reports for several diseases. Since antioxidants are essential components of human machinery, why these adverse results? Final answer has yet to come.

\section{Have Antioxidants Lost their grace or glory?}

Absolutely not, then why are they getting such a punitive punishment? Why antioxidants, once called as miracle tablets, are being suddenly treated as toxic capsules? Where have we faultered? Let us give a pause and reorganize ourselves. The major flaw has been to derive tall, biased conclusions from premature observations. Antioxidant supplements never serve as elixies of life or superhorses of strength or brook of longevity. We coined these adjectives for them for surfeit glory. Now they are being ridiculed because over a passage of time they failed to live upto the expectations, we expected. Excess of everything is bad and the same is true for antioxidants. However we must understand that they are God sent wonder molecules to protect aerobes from the on slaught of ROS, lest the body will perish, without antioxidant $F R$ will undoubtedly cause cell injury and death and that life will be impossible without them. Thus, radiance of antioxidants can not be undermined. They are essential spokes of human machine, work as a team and brilliantly rein the concentration of ROS within evolutionary required levels. They do so in several ways, first they scavenge FR above normal level, second stretch their action in the event of enhanced FR generation, third reduce/maintain the concentration of reactive non-radicals, fourth repair the damages, fifth destroy the damaging molecules and sixth extending their helping arm to perform many non-antioxidant functions.

\section{Future Studies}

The simmering controversies regarding antioxidants can be resolved only through systematic and integrated experimental and clinical approach. Two points are already settled: antioxidants are essential for human life and that the role of different antioxidants may differ cell/tissue wise. Functions of endogenous antioxidants are known and decided. We have little option to negotiate them. This leaves us with dietary antioxidants. To settle the rank order and relative importance of dietary antioxidants, the right sequence of approach should be : first, to test the antioxidant activity of various natural molecules, expected to possess antioxidant activity, in vitro, second to follow them in cell culture studies, third testing them in normal and diseased animal models, fourth to examine the authenticity of these observations, in human observational studies, fifth to follow them with case control studies and supplemental studies, and sixth conclusion so derived should finally be verified through double blind placebo controlled interventional studies, which are undoubtedly gold standards. To cap them all, all these studies must be carried out in different set of prooxidizing environment encountered in humans, lest we will continue to land in conundrum (14). French scientist has rightly said, "Science is built with facts as house is with stones. But the collection of facts is no more a science, than a heap of stone is house". Instead of talking chalk and cheese, let us use our collective sapience and resources to resolve grotesque antioxidant puzzle from convulsions of confusions.

Both authors are past Presidents of ACBI and Editor in chief of IJCB.

\section{REFERENCES}

1. Singh PP, Gupta S, Barjatiya M, Mamtha G Pand, Adhikari J. Free radicals and antioxidants in health and disease: Concordance and Discordance. Oxidant antioxidant dovetail hypothesis. Let $s$ not sprint before we stand Chowdhary Offset Udaipur 2007; 1-31.

2. Singh PP, Pendse AK, Bomb BS, Barjatiya MK, Ghosh R. Free radicals and antioxidants: Sort out facts from fiction. Chowdhary Offset Udaipur 1999; XV-XIX.

3. Baxi M, Baxi J, Adhikari D, Singh PP. Clinicopathological profile of fibrocystic disease of breast with and without malignancy and assessment of efficacy of vitamin $E$ supplementation in mastalgia due to fibrocystic disease: Results from a tertiary care centre in Western Nepal $42^{\text {nd }}$ World Congress of the Int. Soc. Surg. Montreal, Canada 2007; 168.

4. Hathcock JN, Azzi A, Blunberg J, Bray, et al. Vitamin E and $\mathrm{C}$ are safe across a broad range of intakes. Am J Clin Nutr 2006; 81: 736-46.

5. McCormick DB. The dubious use of vitamin mineral supplements in relation to cardiovascular disease. Am J Clin Nutr 2006; 84: 680-81.

6. Valko M, Leibfritz D, Moncol J, Cronin MTD, et al. Free radical and antioxidants in normal physiological functions and human disease. Int J Biochem Cell Biol 2007; 39: 44-84.

7. Clark MW, Buznett JR. Vitamin E in human health and disease. Crit Rev Clin Lab Sci 2008; 45: 417-50. 
8. Bjelakovic G, Nikolova D, Simonetti RG, Gludd C.Antioxidant supplements for preventing gastrointestinal cancers. The Cochrane Collaboration. Wiley Pub 2008; 1-78.

9. Verrax J, Calederon PB. The controversial place of vitamin $C$ in cancer treatment. Biochem Pharmacol 2008; 76 : 1644-52.

10. Singh S, Mahdi F, Singh PP. Insinuating role of free radicals and placating behavior of antioxidants in diabetes mellitus. J Phys 2009; IX: 35-38.

11. Gaziono JM, Glynn RJ, Christen WG, Kurth J, et al. Vitamin $E$ and $C$ in the prevention of prostate and total cancer in men: The Physicians health study II randomized controlled trials. JAMA 2009; 301: 52-62.
12. Lin J, Cook NR, Albert C, Zeharris E, et al. Vitamin C and E and beta-carotene supplementation and cancer risk: $A$ randomized controlled trial. $\mathrm{JNCl} 2009$; 101: 14-23.

13. Lipman SM, Klein EA, Goodman PJ, Lucia MS, et al. Effect of selenium and vitamin $E$ on risk of prostate cancer and other cancers: The selenium and vitamin $\mathrm{E}$ cancer prevention trial (SELECT). JAMA 2009; 301: 39-51.

14. Sharma P, Singh PP. Antioxidant conundrum in human health: Where we stand. $29^{\text {th }}$ Ann. Conf. ACBI Jaipur, India 2003; 22. 